\title{
Unusual Presentation of Wilms' Tumor as Umbilical Granuloma
}

\begin{abstract}
We report an unusual presentation of a Wilms' tumor in an 8-month-old child, incidentally detected by ultrasonography for an umbilical granuloma. A patent vitellointestinal duct anomaly required surgical excision in the same sitting as the nephroureterectomy. The case is reported for the unusual coexistence and the management implications.
\end{abstract}

Keywords: Incidental diagnosis, umbilical granuloma, vitellointestinal duct anomaly, Wilms'tumor

\section{Introduction}

Umbilical granuloma is common in infants and usually responds to common salt local application. It is to be borne in mind that not all umbilical lesions are granulomas and when not responding to treatment getting ultrasonography (USG) to rule out vitellointestinal duct (VID) or urachal anomalies is prudent. ${ }^{[1]}$ In the index case, the USG also picked up a Wilms' tumor in the right kidney which has not been reported in literature previously.

\section{Case Report}

A full-term male child had a persistent red fleshy mass at the umbilicus not responding to local application of antibiotic ointment and silver nitrate. $\mathrm{He}$ was well with no complaints other than a minimal serosanguinous discharge from the umbilicus. At 7 months of age, he was referred for surgical excision of the umbilical mass. An USG of the abdomen done just before referral, however, picked up a large right renal tumor. A Wilms' tumor was diagnosed on fine-needle aspiration cytology at our center. Contrast-enhanced computed tomography of the abdomen revealed a $9 \mathrm{~cm} \times 6 \mathrm{~cm} \times 8 \mathrm{~cm}$ tumor arising from the lower pole of the right kidney [Figure 1a]. The tumor showed a significant reduction in size after four cycles of chemotherapy with Actinomycin D and vincristine. At laparotomy, a broad-based Meckel's diverticulum with a patent duct leading up

This is an open access journal, and articles are distributed under the terms of the Creative Commons Attribution-Non Commercial-ShareAlike 4.0 License, which allows others to remix, tweak, and build upon the work non-commercially, as long as appropriate credit is given and the new creations are licensed under the identical terms.

For reprints contact: reprints@medknow.com to the umbilical granuloma [Figure 1b] was found. Wedge resection of the Meckel's diverticulum was done along with a right radical nephroureterectomy. The child had an uneventful postoperative period. Histopathology confirmed triphasic Wilms' tumor [Figure 2]. He is doing well at 6 months of follow-up.

\section{Discussion}

Wilms' tumor is the most common childhood abdominal malignancy forming $6 \%$ of all childhood cancers with a 5 -year survival rate of nearly $90 \% .{ }^{[2]}$ Presenting features include abdominal mass, pain, hematuria, and fever. In the normal population, there is a $2 \%$ incidence of VID anomalies which may remain silent throughout life. The spectrum of anomalies includes fistula, sinus tract, cyst, mucosal remnants, and congenital bands. A study of 16 infants with VID revealed the most common presentation to be patent VID with visible bowel loop and/or fecal discharge with an umbilical granuloma seen only in $12.25 \%$ of patients. ${ }^{[3]}$

Intra-abdominal malignancy is known to cause umbilical deposits in adults, also called Sister Mary Joseph's nodule, secondary to spread through the lymphatics and venous channels draining along the abdominal wall. ${ }^{[4]}$ This phenomenon is not known in children, and the umbilical mass, in this case, was soft and granulomatous as opposed to hard and skin covered. It would appear that the two conditions existed coincidentally but the persistence of the granuloma at 7 months age led to

How to cite this article: Hegde SG, Menon P, Narasimha Rao KL, Nada R. Unusual presentation of Wilms' tumor as umbilical granuloma. Indian J Med Paediatr Oncol 2018;39:413-4.

\section{Shalini Gajanan \\ Hegde, \\ Prema Menon, Katragadda Lakshmi Narasimha Rao, Ritambhra Nada ${ }^{1}$}

Departments of Pediatric Surgery and ${ }^{1}$ Histopathology, Post Graduate Institute of Medical Education and Research, Chandigarh, India

\section{Address for correspondence:} Dr. Shalini Gajanan Hegde, Department of Pediatric Surgery, No: 49, St. Johns Medical College Hospital, Sarjapur Road, Bengaluru - 560 034, Karnataka, India.

E-mail: shal.hegde@gmail.com

Access this article online

Website: www.jjmpo.org

DOI: 10.4103/ijmpo.ijmpo_245_17 Quick Response Code:

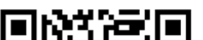




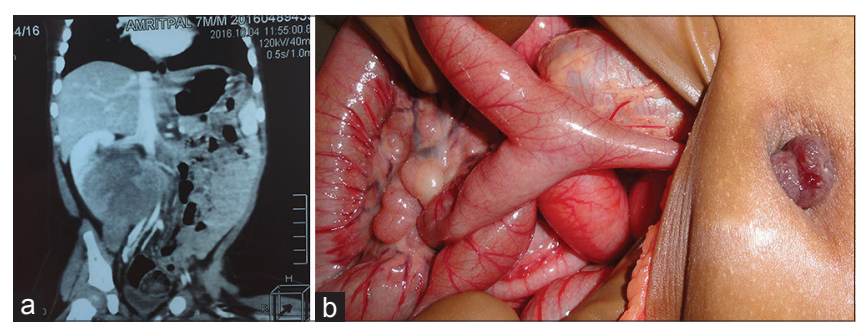

Figure 1: (a) Contrast-enhanced computed tomography scan of the abdomen shows a large right renal tumor. (b) Intraoperative photograph of the umbilical granuloma connected with a patent vitellointestinal duct

the USG detection of the VID and the renal tumor which could be excised in the same sitting without any additional morbidity.

Wilms' tumor is less frequent in infants but associated with a better prognosis. ${ }^{[5]}$ Due to an association with favorable histology, they may be treated with surgical resection alone. Early detection is possible if frequent well-child check-ups are done in the $1^{\text {st }}$ year of life. If our case did not have the associated granuloma, he may have presented later with metastasis. A literature search of surgical conditions that preceded the diagnosis of Wilms' tumor revealed only one report of a 5-year-old that presented with a perforated appendix and was detected to have a renal mass on imaging. The child underwent an appendectomy followed by an open biopsy of the renal mass which revealed Wilms' tumor. ${ }^{[6]}$

\section{Conclusion}

This is an unusual presentation of Wilms' tumor in an infant which has not been reported before. It is hoped that early management will improve the long-term outlook for this patient.

\section{Declaration of patient consent}

The authors certify that they have obtained all appropriate patient consent forms. In the form the patient(s) has/have given his/her/their consent for his/her/their images and other clinical information to be reported in the journal. The patients understand that their names and initials will not be published and due efforts will be made to conceal their identity, but anonymity cannot be guaranteed.

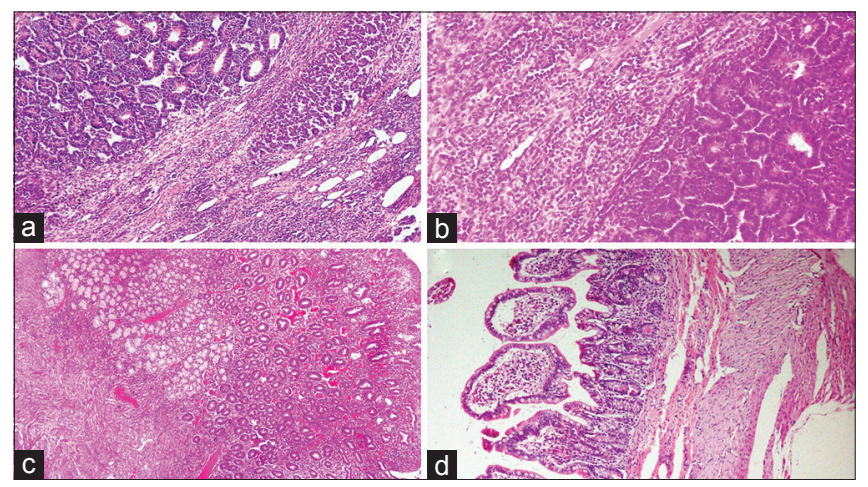

Figure 2: Histopathological picture $(\mathrm{H}$ and $\mathrm{E}, \times 200)$ shows (a) Part of renal tumor with epithelial and focal stromal component. (b) Blastemal components with focal stromal component. (c) Umbilical granuloma showing colonic mucosa with heterotopic Brunner's glands in submucosa and (d) Diverticulum with small intestinal lining epithelium. No heterotropia was noted

\section{Financial support and sponsorship}

Nil.

\section{Conflicts of interest}

There are no conflicts of interest.

\section{References}

1. Sarwar U, Javed M, Wright T, Dawson A, Wilson-Jones N. These umbilical lesions weren't granulomas after all. J Fam Pract 2016;65:E1-3.

2. Weirich A, Ludwig R, Graf N, Abel U, Leuschner I, Vujanic GM, et al. Survival in nephroblastoma treated according to the trial and study SIOP-9/GPOH with respect to relapse and morbidity. Ann Oncol 2004;15:808-20.

3. Kadian YS, Verma A, Rattan KN, Kajal P. Vitellointestinal duct anomalies in infancy. J Neonatal Surg 2016;5:30.

4. Larbcharoensub N, Pongtippan A, Pangpunyakulchai D, Phongkitkarun S, Lertsithichai P, Dejthevaporn TS, et al. Sister mary joseph nodule caused by metastatic desmoplastic small round cell tumor: A clinicopathological report. Mol Clin Oncol 2016;5:557-61.

5. Lamb MG, Aldrink JH, O’Brien SH, Yin H, Arnold MA, Ranalli MA, et al. Renal tumors in children younger than 12 months of age: A 65-year single institution review. J Pediatr Hematol Oncol 2017;39:103-7.

6. Li A, Asch M, Lasky J $3^{\text {rd }}$, Sieger L, Lee SL. The surgical management of a stage III wilms tumor presenting with perforated appendicitis. J Pediatr Hematol Oncol 2012;34:e193-4. 